\title{
Knowledge and attitudes of Singapore schoolchildren learning cardiopulmonary resuscitation and automated external defibrillator skills
}

Phek Hui Jade $\underline{K u a}^{1}$, MBBS, MRcs, Alexander $E \underline{\text { White }}{ }^{2}$, JD, MPH, Wai Yee $\underline{N g}^{3}$, BSc, Stephanie Fook-Chong ${ }^{4}$, MSc, CStat, Eileen Kai Xin $\mathrm{Ng}^{2}$, BN, Yih Yng $\mathrm{Ng}^{5}$, MBBS, MPH, Marcus Eng Hock Ong ${ }^{6,7}$, MBBS, MPH

\begin{abstract}
INTRODUCTION Victims of out-of-hospital cardiac arrests require timely cardiopulmonary resuscitation (CPR) and early defibrillation. Callers to emergency medical services are asked to provide dispatcher-guided responses until an ambulance arrives. Knowing what to expect in such circumstances should reduce both delay and confusion.

METHODS This study was conducted among schoolchildren aged 11-17 years using ten-item pre- and post-training surveys. We aimed to observe any knowledge and attitude shifts regarding CPR and automated external defibrillator (AED) use subsequent to the training.

RESULTS A total of 1,196 students across five schools completed the pre- and post-training surveys. Survey questions tested basic CPR knowledge and attitudes towards CPR and AED use. The overall response rate was $80.8 \%$ and $81.5 \%$ in the pre- and post-training surveys, respectively. There was a statistically significant improvement in the students' CPR knowledge. The number of students who selected all the correct answers for the knowledge-based questions in the posttraining survey increased by $64.7 \%$ (95\% confidence interval $61.9 \%-67.5 \% ; p<0.001$ ). There was also an improvement in their willingness to administer CPR (likely/very likely to administer CPR pre-training vs. post-training: $13.0 \%$ vs. $71.0 \%$; $p<0.001$ ) and use AED (likely/very likely to administer AED pre-training vs. post-training: $11.7 \%$ vs. $78.0 \% ; p<0.001$ ) after training.

CONCLUSION The training programme imparted new information and skills, and improved attitudes towards providing CPR and using AED. However, some concerns persisted about hurting the victim while performing CPR.
\end{abstract}

Keywords: AED, cardiac arrest, CPR, school, training

\section{INTRODUCTION}

Cardiopulmonary resuscitation (CPR) skills and the willingness to act can be taught and ingrained at an early age, as has been done in several cities and countries. ${ }^{(1-5)}$ Teaching schoolchildren CPR and automated external defibrillator (AED) use are considered important components in any locale's strategy to increase out-of-hospital cardiac arrest (OHCA) survival rate. OHCA survival rate is correlated with bystander CPR rate ${ }^{(6-9)}$ and has an even stronger link with the quality of bystander CPR. ${ }^{(10)}$ In Singapore, the bystander CPR rate plateaued at just over 20\% in the early 2000s and has remained at this level for many years. ${ }^{(11)}$ Motivated local physicians developed a training programme to help increase the bystander CPR rate ${ }^{(12)}$ and in this way, closed the gap between Singapore and other countries that are considered leading models for good OHCA survival rates.

Compared to Singapore $(11 \%),{ }^{(11)}$ Europe $^{(13)}$ has a greater OHCA survival rate (median $23.3 \%$ for witnessed shockable rhythm arrests). Such high rates are attributable to various pre-hospital improvements and public training initiatives. ${ }^{(14-18)}$ Pertinent to our study, Norway, ${ }^{(19-21)}$ Sweden ${ }^{(14,17)}$ and Denmark, ${ }^{(15)}$ for example, have successfully mandated various school-based CPR and AED trainings over the years as part of their overall strategy to improve OHCA survival outcomes..$^{(5,15,19-21)}$ The success in Europe and Seattle ${ }^{(22)}$ inspired Singapore to adopt a multifaceted approach to improve bystander CPR rates.

This study focused on the implementation of the first schoolbased training curriculum piloted in Singapore. School-based training is an effective and sustainable method used to train large numbers of future adult members of society. ${ }^{(5,22)}$ Recently, the World Health Organization endorsed the 'Kids Save Lives' joint statement, which postulates that an effective method of improving bystander CPR is to provide training in schools. ${ }^{(23)}$ In the present study, we aimed to measure, assess and report any immediate knowledge gain and attitude shifts experienced by students attending the training.

\section{METHODS}

We created a training programme named DARE, or DispatcherAssisted first REsponder. DARE is a 45-minute programme consisting of a 13-minute video and hands-on practice of CPR and AED use on a manikin. The programme's core teaching points were to: (a) immediately call '995' for an ambulance and stay on the line; (b) do chest compressions by pushing hard and fast on the centre of the chest; and (c) direct someone to get

\footnotetext{
${ }^{1}$ Department of Emergency Medicine, KK Women's and Children's Hospital, ${ }^{2}$ Unit for Pre-hospital Emergency Care, ${ }^{3}$ Health Services Research, Division of Research, Singapore General Hospital, ${ }^{4}$ Centre for Quantitative Medicine, Duke-NUS Medical School, ${ }^{5}$ Medical Department, Singapore Civil Defence Force, ${ }^{6}$ Department of Emergency Medicine, Singapore General Hospital, ' Health Services and Systems Research, Duke-NUS Medical School, Singapore

Correspondence: A/Prof Marcus Eng Hock Ong, Senior Consultant, Department of Emergency Medicine, Singapore General Hospital, Outram Road, Singapore 169039. marcus.ong.e.h@singhealth.com.sg
} 
an AED and use it. Since Singapore has a dispatcher-assisted CPR protocol, the trainer roleplayed as a dispatcher during the hands-on section of the training session. This dispatcher role was central to the simulation training. The training familiarised students with the dispatcher's instructions that are usually given during a real-life OHCA call and the actions that the caller would be asked to perform.

The training programme was designed to keep schoolchildren and young people engaged. The video was scripted to be humorous at times while conveying information on a very serious subject. The actors included schoolchildren and a popular contemporary Singapore actor. The video content was divided into various chapters, beginning with an introductory stage play in which the main character collapsed from a cardiac arrest and the children, aided by the dispatcher, successfully resuscitate him. Afterwards, the video delved into the pathophysiology of a cardiac arrest using layman's terms and animation for easy comprehension. The video then took on a heartwarming note, with an actual OHCA survivor and his rescuers sharing their real-life story to inspire and motivate the audience.

After the video, students were split into small groups to begin the hands-on training. Small group configurations enhance skill learning by allowing facilitators to easily observe and work with students on proper technique and skills implementation. During the hands-on segment, students were taught to dial the emergency medical number, put the dispatcher on speaker before placing the phone near the victim's head, perform chest compressions and use the AED safely.

This study was conducted in Singapore, with approval from the SingHealth Centralised Institutional Review Board (CIRB) at Singapore General Hospital (CIRB Ref 2013/1020/E). Our study cohort included five schools: one primary school (elementary school; School A), two secondary schools (junior high schools; Schools B and C) and two junior colleges (high schools; Schools D and E). Students were aged 11-17 years. All the students from the primary school and one of the secondary schools were female. The remaining three schools had gender-balanced participation. One school specialised in teaching students with learning challenges. All schools had a racial mix (students were ethnically Chinese, Malay or Indian) representing the main ethnic groups in Singapore.

Two out of five schools (Schools C and D) completed the surveys electronically by accessing it on Google Docs using smartphones at the training site, while the others responded using paper surveys. Pre- and post-training questionnaires (see Appendices 1 and 2, respectively) contained ten questions across two sections. Section 1 consisted of five questions (Questions 1-5) designed to assess students' acquired knowledge on CPR and AED. Section 2 consisted of four questions (Questions 6-9) to assess students' shift in attitudes and beliefs about CPR and AED use. An additional question (Question 10) asked about their preferred method of CPR/AED instruction, assessing what they thought they would like to have in a training session (before the intervention) and what they liked about the training after experiencing it.

The 45-minute training programme was the assessed intervention. Pre- and post-training surveys were conducted using the same questionnaire on the same group of students from these five schools to assess facets of the training programme. All the surveys were anonymous and were matched using a unique student identifier. Assessed outcomes included changes in student knowledge of CPR and AED use (Questions 1-5), and attitudes towards CPR and AED use (Question 6-9). Question 10 assessed the students' expectations of the CPR/AED training programme and their assessment of it after attending the session. Unanswered questions were treated as missing values and the results reported were based on valid responses.

To assess pre- and post-training knowledge about CPR and AED use, the proportions of students who correctly answered each of the five knowledge questions were calculated. McNemar's chisquare test was used to determine whether there was a statistically significant improvement in knowledge before and after training. The overall difference in pre- and post-training knowledge was determined by calculating the total number of students who answered all five questions correctly. McNemar's test was also used to compare the overall difference between the pre- and post-training knowledge assessments. This data was presented in 95\% confidence intervals (Cls).

For Questions 6-9, the proportions of the types of attitudes and beliefs about CPR/AED use were calculated for both the pre- and post-training surveys. Due to small numbers, the 'very likely' and 'likely' responses, and the 'unlikely' and 'very unlikely' responses were grouped together for Questions 6 and 8. McNemar's test was used to compare the overall difference between pre- and post-training attitudes and beliefs. 95\% Cls were also calculated for this data. A p-value $<0.05$ on McNemar's test was considered to be statistically significant. All tests were twotailed. Data was analysed using Stata version 13.0 (StataCorp, College Station, TX, USA).

\section{RESULTS}

Overall, 1,196 students participated in the survey. The majority of the participants were girls. The overall mean age of the students was 14 years. The overall response rate was $80.8 \%$ and $81.5 \%$ for the pre- and post-training surveys, respectively. Response rates, by school, are presented in Table I.

All survey questions were in multiple-choice format. Compared to only $4.2 \%$ in the pre-training survey, $68.9 \%$ of the students answered all the knowledge-testing questions correctly in the post-training survey (Table II). Of all students surveyed, the two junior colleges produced the highest rate of perfect scores (42.1\%) in the knowledge-testing section of the post-training survey. The two secondary schools were next (20.8\%), followed by the single primary school (5.9\%). School D, a junior college, achieved the highest improvement in perfect scores on the knowledge-testing questions with a difference of $88.2 \%(95 \% \mathrm{Cl} 85.1 \%$ to $91.2 \%$; $\mathrm{p}<0.001$ ) between the pre- and post-training survey. Conversely, School B, a secondary school, improved the least between the pre- and post-training survey $(0.0 \%$ vs. $11.1 \%, 95 \% \mathrm{Cl}-2.9 \%$ to $22.5 \% ; p=0.063)$.

Importantly, students improved their rate of correct responses for the safety question (Table III, Question 1), which asked what 
Table I. Overall response rates for five schools.

\begin{tabular}{|c|c|c|c|c|c|c|}
\hline Variable & $\begin{array}{l}\text { Overall } \\
(n=1,196)\end{array}$ & $\begin{array}{l}\text { School A } \\
(n=261)\end{array}$ & $\begin{array}{l}\text { School B } \\
(n=45)\end{array}$ & $\begin{array}{l}\text { School C } \\
(n=325)\end{array}$ & $\begin{array}{l}\text { School D } \\
(n=499)\end{array}$ & $\begin{array}{l}\text { School E } \\
(n=66)\end{array}$ \\
\hline Mean age (yr) & 14 & 11 & 11 & 15 & 17 & 17 \\
\hline Pre-training survey & 80.8 & 82.3 & 42.1 & 100.0 & 85.9 & 81.7 \\
\hline Post-training survey & 81.5 & 82.3 & 38.6 & 100.0 & 93.5 & 61.7 \\
\hline
\end{tabular}

Table II. Students who answered all knowledge-testing questions correctly $(n=1,196)$.

\begin{tabular}{|llll|}
\hline School & \multicolumn{2}{c|}{ No. (\%) } & P-value \\
\cline { 2 - 3 } & Pre-training & Post-training & \\
\hline All five schools & $50(4.2)$ & $824(68.9)$ & $64.7(61.9$ to 67.5$)$ \\
\hline School A $(n=261)$ & $12(4.6)$ & $71(27.2)$ & $22.6(17.1$ to 28.1$)$ \\
\hline School B $(n=45)$ & $0(0)$ & $5(11.1)$ & $11.1(-2.9$ to 22.5$)$ \\
\hline School C $(n=325)$ & $9(2.8)$ & $244(75.1)$ & $72.3(67.1$ to 77.6$)$ \\
\hline School D $(n=499)$ & $27(5.4)$ & $467(93.6)$ & $88.001(85.1$ to 91.2$)$ \\
\hline School E $(n=66)$ & $2(3.0)$ & $37(56.1)$ & $53.1(39.5$ to 66.6$)$ \\
\hline
\end{tabular}

$\mathrm{Cl}$ : confidence interval

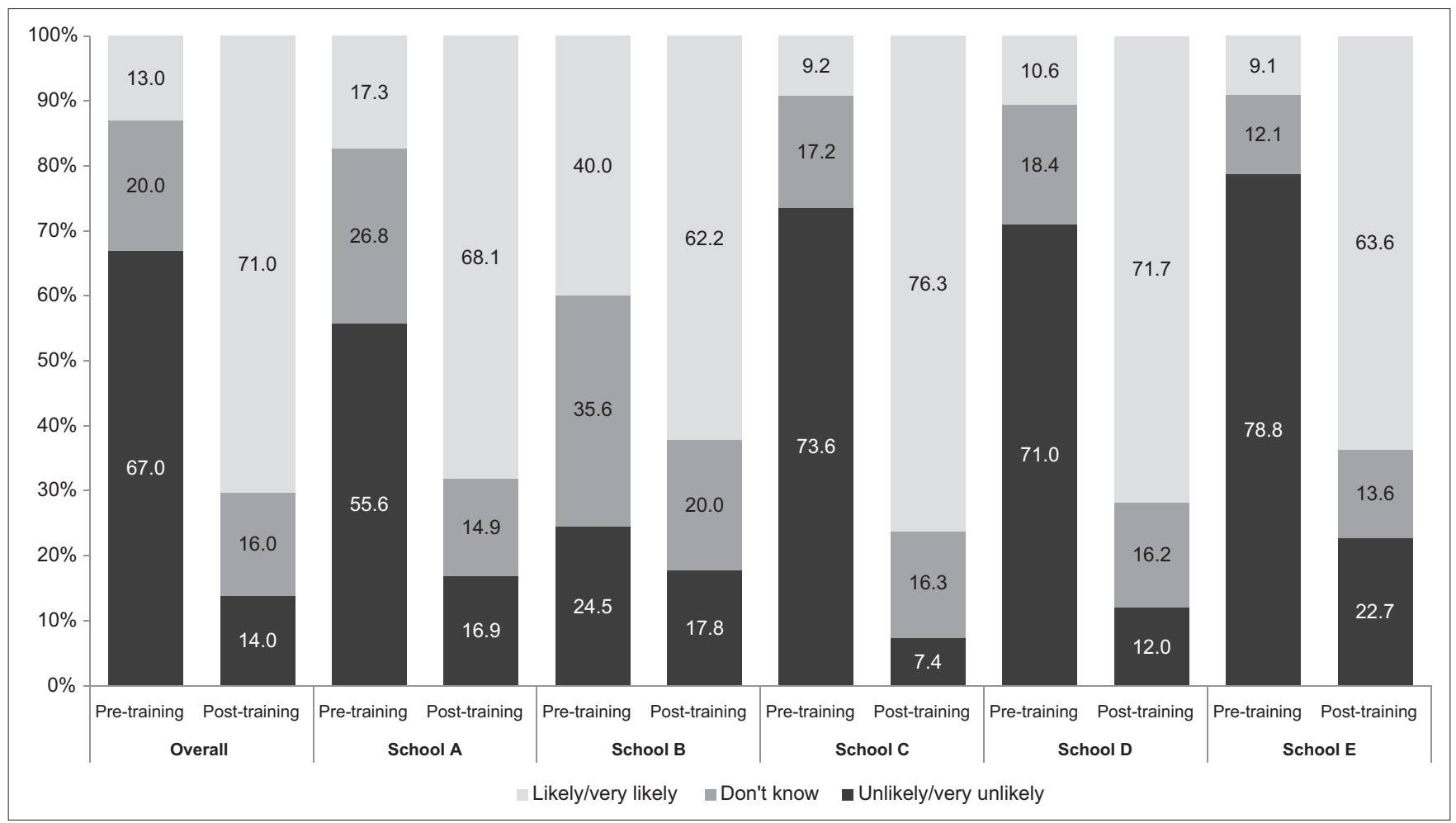

Fig. 1 Bar chart shows responses to Question 6, 'How likely are you to perform CPR on a collapsed person today?' CPR: cardiopulmonary resuscitation

they should do first if they see someone collapse (pre-training vs. post-training: $36.6 \%$ vs. $93.8 \%$, difference $57.2 \%, 95 \% \mathrm{Cl}$ $54.3 \%-60.1 \% ; p<0.001)$. Referring to what emergency number to call, Question 2 had the smallest margin of improvement overall (difference $26.9 \%$ ) presumably because students were already familiar with the right answer. However, one school did slightly worse with Question 2 in the post-training survey (95.6\%) when compared to pre-training levels (100.0\%), although the difference was not statistically significant $(p=0.500)$. All schools showed improvement on Question 3, which asked what one should do after getting through to the dispatcher, and is a fundamental learning point in the training (pre-training vs. post-training: $56.4 \%$ vs. $97.7 \%$; $<0.001)$. Questions 4 and 5 pertained to depth and rate of compressions, respectively. Overall, the margins of improvement for these questions from pre- to post-training surveys for all schools were $54.0 \%$ and $59.6 \%$, respectively.

In the pre-training survey, $67.0 \%$ of students from the five schools chose either 'unlikely' or 'very unlikely' to perform CPR on a collapsed person (Fig. 1). Only 13.0\% selected either 'likely' or 'very likely' to perform CPR on a collapsed person while $20.0 \%$ 
Table III. Percentage of all correct answers for the knowledge-testing questions (Questions 1-5).

\begin{tabular}{|c|c|c|c|c|c|c|}
\hline \multirow[t]{3}{*}{ Question } & \multicolumn{6}{|c|}{ Students who answered all questions correctly (\%) } \\
\hline & \multicolumn{2}{|c|}{ Overall $(n=1,196)$} & \multicolumn{2}{|c|}{ School A $(n=261)$} & \multicolumn{2}{|c|}{ School B $(n=45)$} \\
\hline & Pre-training & Post-training & Pre-training & Post-training & Pre-training & Post-training \\
\hline 1 & 36.6 & 93.8 & 14.2 & 85.4 & 15.6 & 55.6 \\
\hline Difference $(95 \% \mathrm{Cl})$ & \multicolumn{2}{|c|}{$57.2(54.3$ to 60.1$)$} & \multicolumn{2}{|c|}{$71.2(65.4$ to 77.1$)$} & \multicolumn{2}{|c|}{$40.0(22.2$ to 57.8$)$} \\
\hline p-value & \multicolumn{2}{|c|}{$<0.001$} & \multicolumn{2}{|c|}{$<0.001$} & \multicolumn{2}{|c|}{$<0.001$} \\
\hline 2 & 72.3 & 99.2 & 65.5 & 98.9 & 100.0 & 95.6 \\
\hline Difference $(95 \% \mathrm{Cl})$ & \multicolumn{2}{|c|}{$26.9(24.3$ to 29.6$)$} & \multicolumn{2}{|c|}{33.4 (27.0 to 39.6$)$} & \multicolumn{2}{|c|}{$-4.4(-12.7$ to 3.8$)$} \\
\hline p-value & \multicolumn{2}{|c|}{$<0.001$} & \multicolumn{2}{|c|}{$<0.001$} & \multicolumn{2}{|c|}{0.500} \\
\hline 3 & 56.4 & 97.7 & 47.1 & 95.4 & 60.0 & 80.0 \\
\hline Difference $(95 \% \mathrm{Cl})$ & \multicolumn{2}{|c|}{41.3 (38.3 to 44.2 ) } & \multicolumn{2}{|c|}{48.3 (41.7 to 54.8$)$} & \multicolumn{2}{|c|}{$20.0(-0.3$ to 40.3$)$} \\
\hline$p$-value & \multicolumn{2}{|c|}{$<0.001$} & \multicolumn{2}{|c|}{$<0.001$} & \multicolumn{2}{|c|}{0.064} \\
\hline 4 & 44.5 & 98.5 & 33.7 & 97.7 & 40.0 & 82.2 \\
\hline Difference $(95 \% \mathrm{CI})$ & \multicolumn{2}{|c|}{54.0 (51.1 to 56.9$)$} & \multicolumn{2}{|c|}{64.0 (57.8 to 70.2$)$} & \multicolumn{2}{|c|}{$42.2(24.3$ to 60.1$)$} \\
\hline $\mathrm{p}$-value & \multicolumn{2}{|c|}{$<0.001$} & \multicolumn{2}{|c|}{$<0.001$} & & 01 \\
\hline 5 & 12.5 & 72.1 & 16.1 & 32.6 & 4.5 & 18.2 \\
\hline Difference $(95 \% \mathrm{Cl})$ & 59.6( & to 62.7$)$ & 16.5 & to 23.0$)$ & 13.7 & to 29.4 ) \\
\hline$p$-value & & 001 & & 01 & & \\
\hline Question & Schoo & $(n=325)$ & Schoc & $n=499)$ & Scho & $(n=66)$ \\
\hline & Pre-training & Post-training & Pre-training & Post-training & Pre-training & Post-training \\
\hline 1 & 48.0 & 98.2 & 42.7 & 99.6 & 37.9 & 87.9 \\
\hline Difference $(95 \% \mathrm{Cl})$ & 50.2( & to 56.0 ) & 56.9 & to 61.5$)$ & 50.0 & to 65.0$)$ \\
\hline$p$-value & & 001 & & 01 & & 01 \\
\hline 2 & 71.1 & 99.4 & 73.6 & 99.8 & 77.3 & 98.5 \\
\hline Difference $(95 \% \mathrm{CI})$ & 28.3( & to 33.7$)$ & 26.2 & to 30.3 ) & 21.2 & to 32.6$)$ \\
\hline $\mathrm{p}$-value & & 001 & & 01 & & 01 \\
\hline 3 & 55.4 & 99.7 & 61.3 & 99.4 & 59.1 & 95.5 \\
\hline Difference $(95 \% \mathrm{Cl})$ & 44.3( & to 50.1 ) & 38.1 & to 42.6$)$ & 36.4 & to 49.5 ) \\
\hline$p$-value & & 001 & & 01 & & 01 \\
\hline 4 & 58.2 & 100.0 & 40.3 & 99.6 & 54.6 & 97.0 \\
\hline Difference $(95 \% \mathrm{CI})$ & 41.8( & to 47.5$)$ & 59.3 & to 63.9$)$ & 42.4 & to 55.9$)$ \\
\hline$p$-value & & 001 & & & & 01 \\
\hline 5 & 6.5 & 77.5 & 14.6 & 95.0 & 16.7 & 65.2 \\
\hline Difference $(95 \% \mathrm{Cl})$ & 71.0( & to 76.5 ) & 80.4 & to 84.0$)$ & 48.5 & to 62.8$)$ \\
\hline$p$-value & & 001 & & & & 01 \\
\hline
\end{tabular}

Correct answers for Questions 1-5 were $a, b, c, b$ and c, respectively. The full questionnaire can be found in the Appendices. AED: automated external defibrillator; $\mathrm{Cl}$ : confidence interval; CPR: cardiopulmonary resuscitation

of students 'did not know'. After the training, the proportion of students who thought they were likely or very likely to perform CPR increased by $58.0 \%$ (likely/very likely to administer CPR pretraining vs. post-training: $13.0 \%$ vs. $71.0 \% ; p<0.001$ ) (Fig. 1). The top reason chosen overall (58.0\%) for why students were less likely to perform CPR (Question 7a) was that they were afraid of accidentally hurting the victim (Fig. 2). The overall response rate for this question increased to $67.0 \%$ (9.0\% increase) in the post-training survey. This increase was driven by junior college students who shifted their response from 'never been taught what to do' (Schools D and E pre-training: 40.0\% and $46.7 \%$ respectively) to 'being afraid of accidentally hurting the victim' (post-training: $70.5 \%$ and $83.3 \%$, respectively). Post training, students indicated that the most important reason why they would perform CPR on a collapsed person (Question 7b) was that they had now been taught how to perform CPR (36.0\%). Almost as many students (34.0\%) responded that they felt it was their duty to help someone in need. Many (26\%) indicated that they felt that they were more likely to help than do harm (Fig. 3).

In the pre-training survey, $86.0 \%$ of students responded that they were either unlikely to use or did not know if they would use an AED (Fig. 4). Before training, $46.0 \%$ of students chose 'I have never been taught what to do', and $40.0 \%$ chose 'I am scared I might accidentally hurt the victim' as reasons why they were less likely to use an AED (Question 9a, Fig. 5). After training, the combined percentage of students who were likely or very likely 


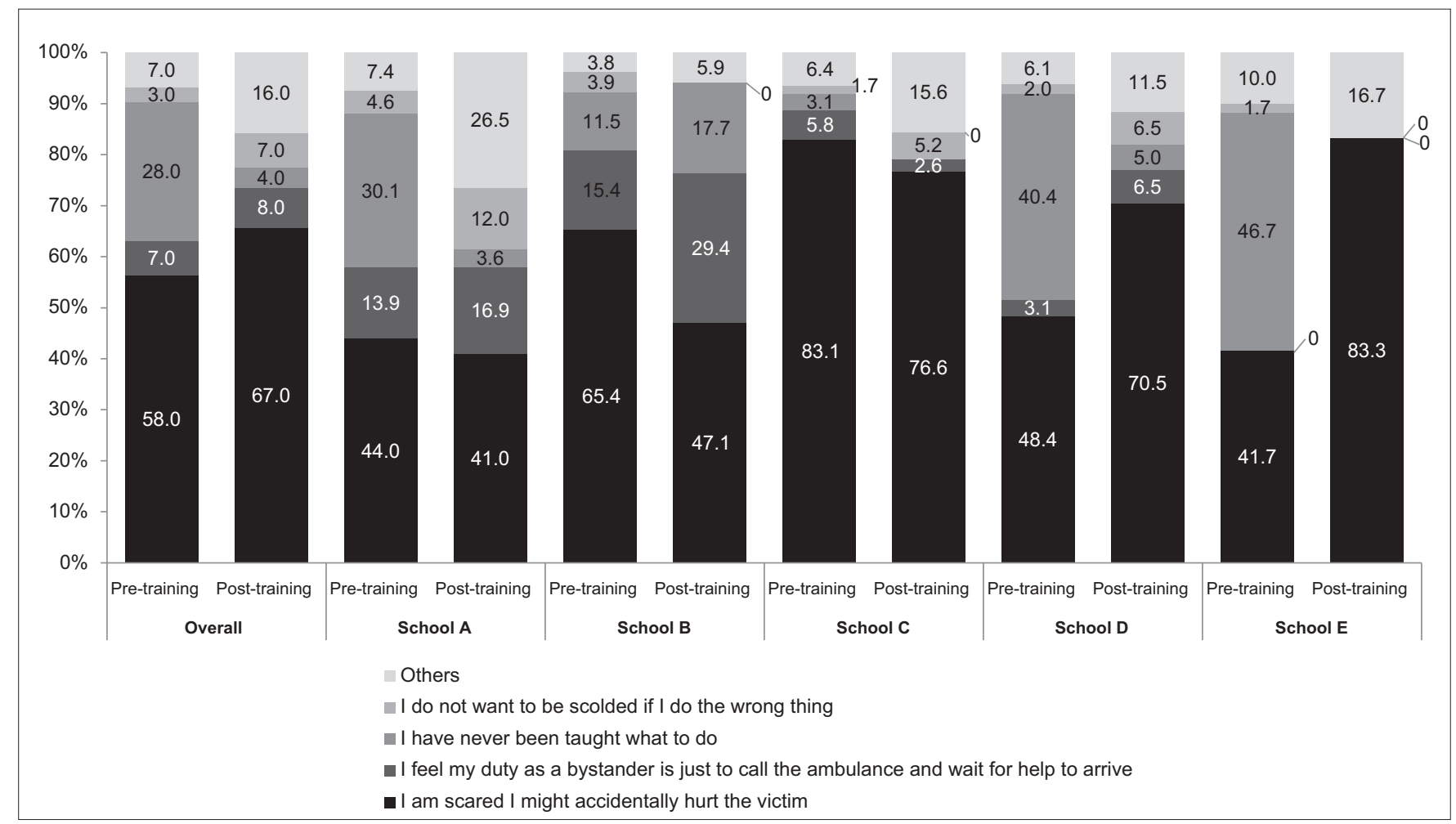

Fig. 2 Bar chart shows responses to Question 7a, 'What is the most important reason why you are less likely to do CPR on a collapsed person today?' CPR: cardiopulmonary resuscitation

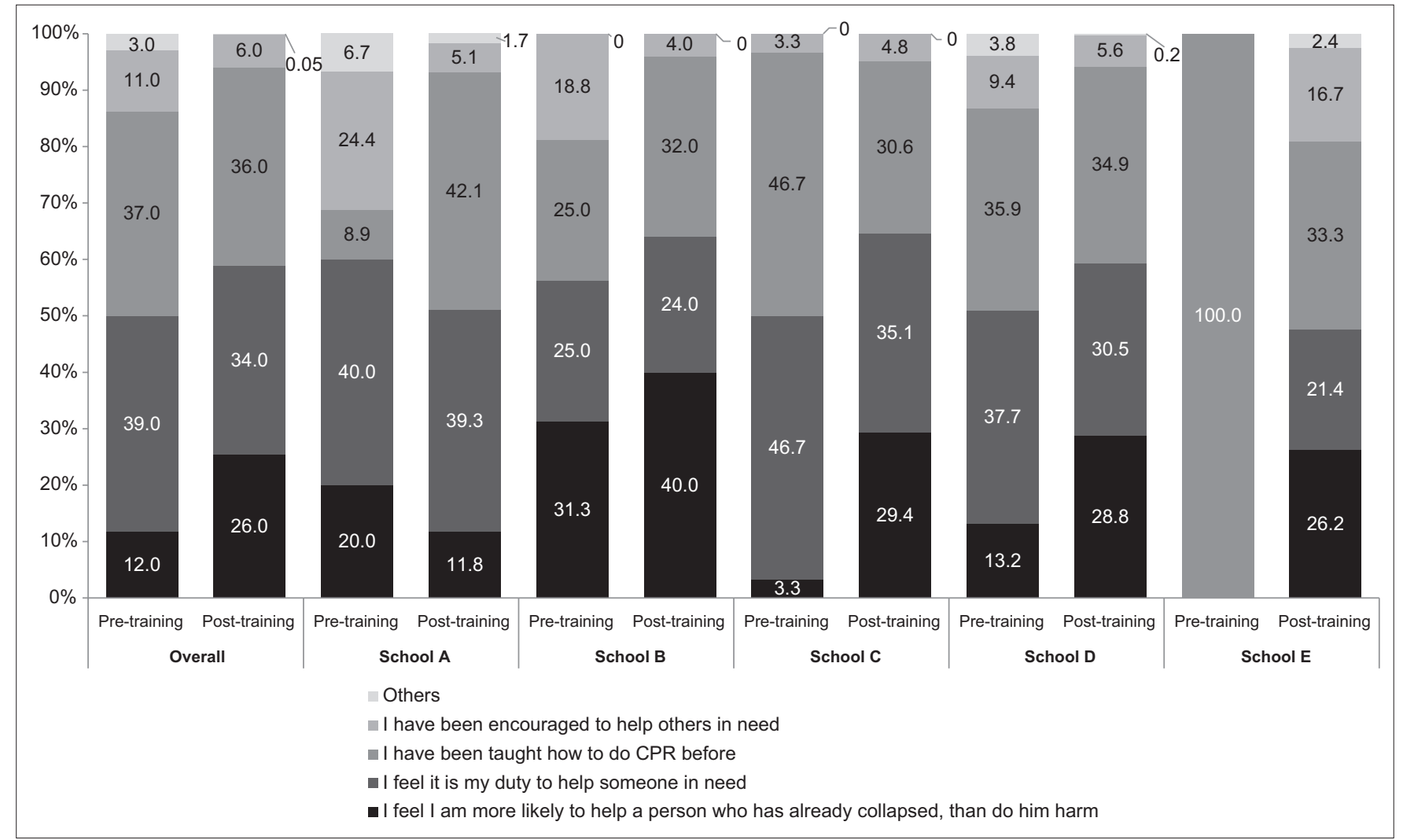

Fig. 3 Bar chart shows responses to Question 7b, 'What is the most important reason why you are likely to do CPR on a collapsed person today?' CPR: cardiopulmonary resuscitation

to use AED increased by $66.3 \%$ (likely/very likely to administer AED pre-training vs. post-training: $11.7 \%$ vs. $78.0 \%$ ) (Fig. 4 ). When asked to identify the most important reason why they were likely to use AED (Question 9b), students most frequently indicated that they had been taught how to use AED (pre-training vs. post-training: $20.0 \%$ vs. $49.0 \%$ ) (Fig. 6). 


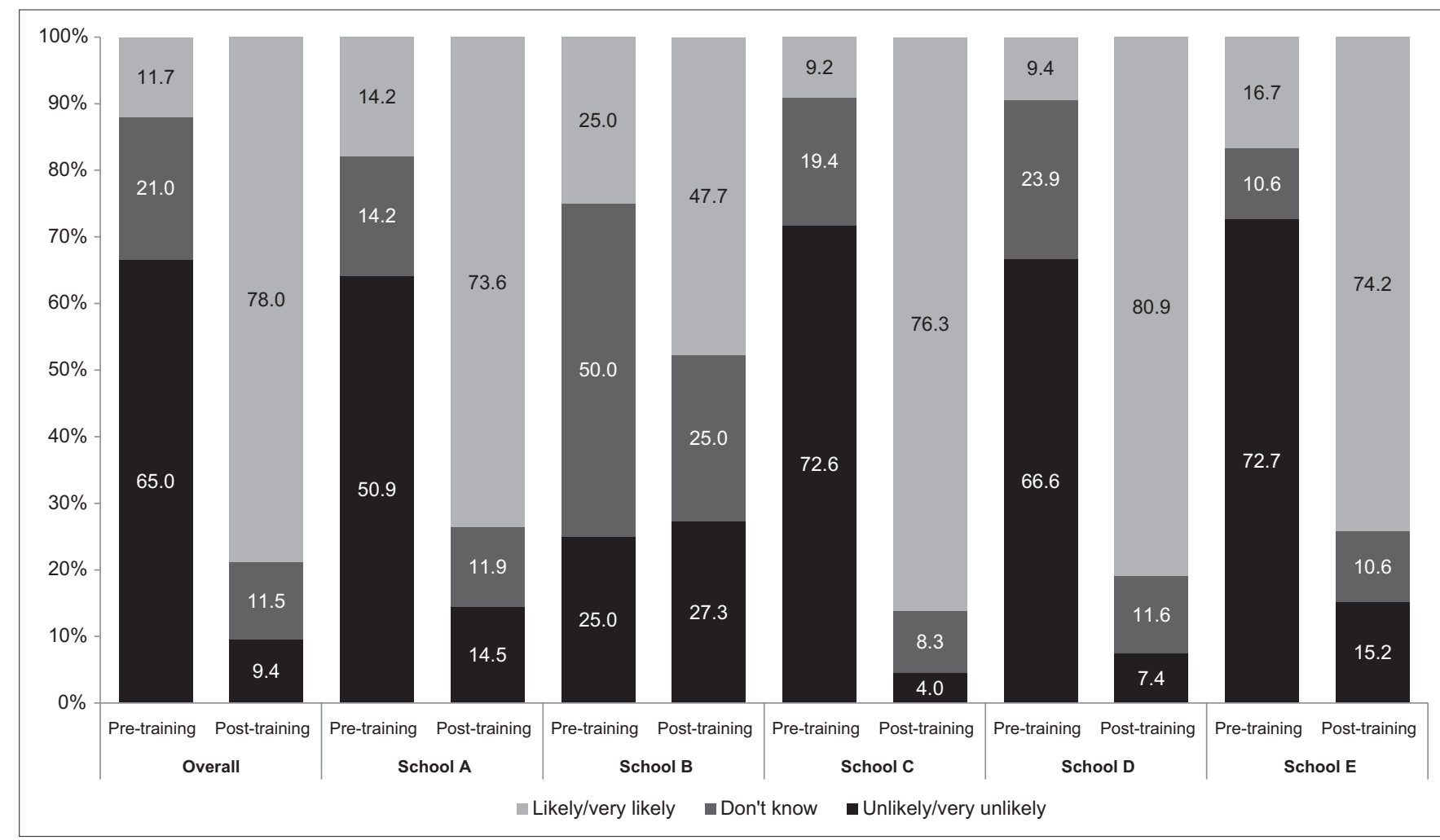

Fig. 4 Bar chart shows responses to Question 8, 'How likely are you to use an AED on a collapsed person today?' AED: automated external defibrillator

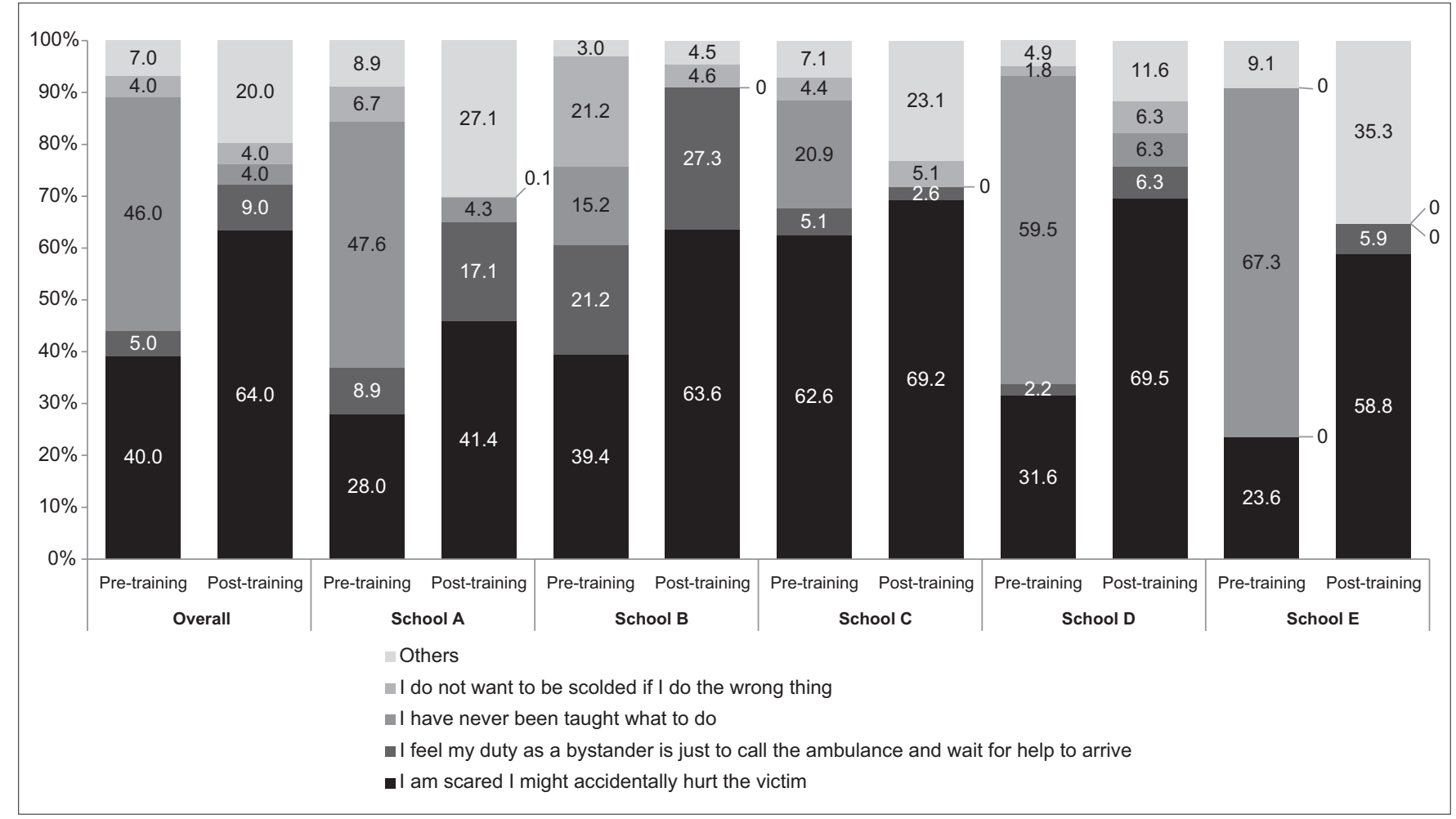

Fig. 5 Bar chart shows responses to Question 9a, 'What is the most important reason why you are less likely to use an AED today?' AED: automated external defibrillator

Fig. 7 shows that the students' top choice for Question 10 was to have a 'humorous video' when learning about CPR and AED, in both the pre- $(28.3 \%)$ and post-training $(35.5 \%)$ surveys. The popularity of a 'humorous video' was followed by 'real-life accounts' (17.1\%) in the pre-training survey, but in the post-training survey a 'person of authority to guide me' $(17.3 \%)$ was the second most popular choice.

\section{DISCUSSION}

This study reported the response of schoolchildren, aged 11-17 years, to the first pilot-tested DARE trainings in the school setting. Training children is an essential component of an overall strategy to transform a society into one that is prepared and motivated to respond to OHCA. This is especially important since 


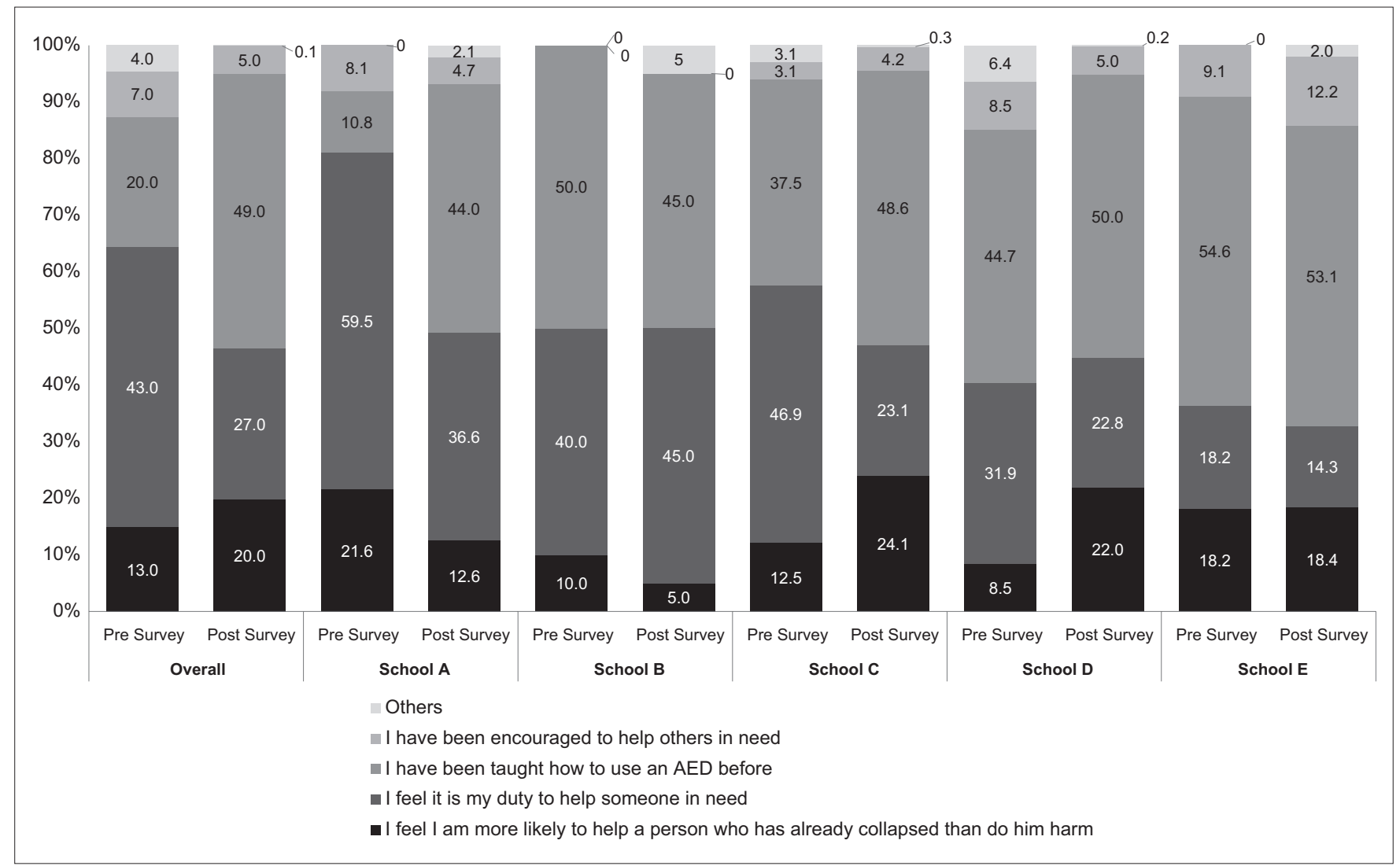

Fig. 6 Bar chart shows responses to Question 9b, 'What is the most important reason why you are likely to use an AED today?' AED: automated external defibrillator

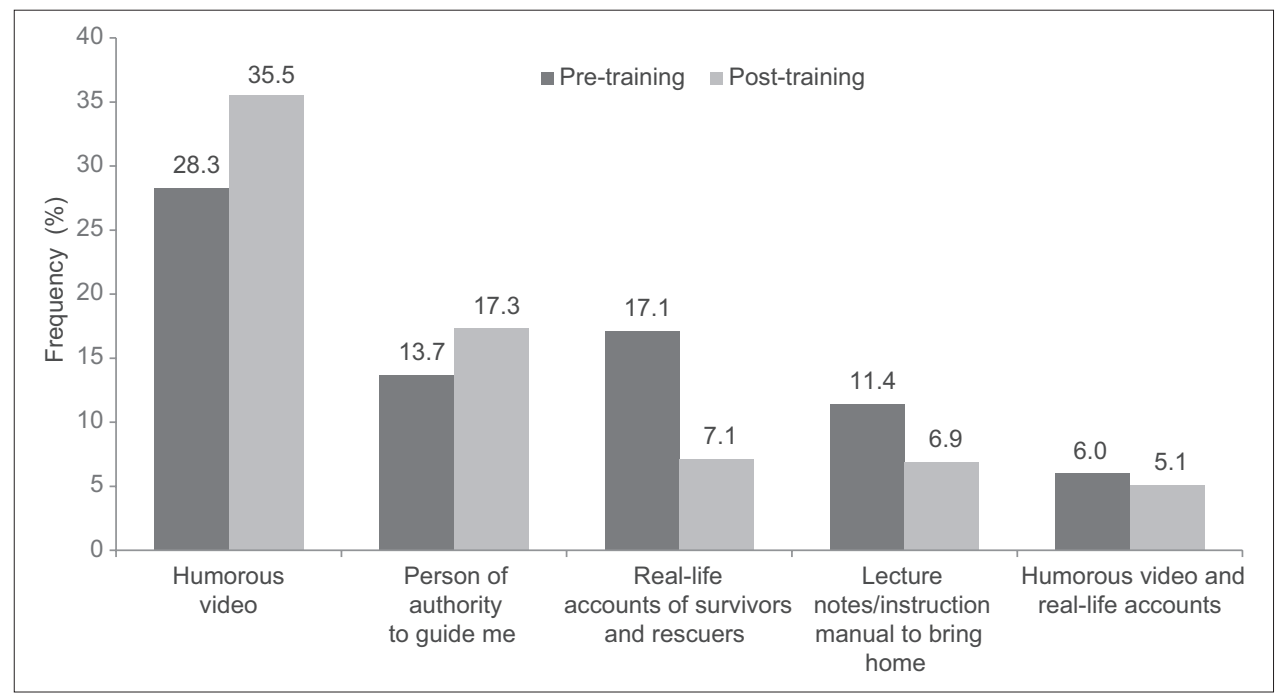

Fig. 7 Bar chart shows the top five pre- and post-training responses to Question 10 ('What would you like to have in a class about CPR/AED?'/'What aspects of this class on CPR/AED did you enjoy?') for all schools. AED: automated external defibrillator; CPR: cardiopulmonary resuscitation

OHCA is a time-sensitive emergency, of which $70 \%$ of cases occur at home or in residential areas and are likely to happen to a family member or someone known to the bystander.

Steps to improve schoolchildren's knowledge and attitudes towards taking emergency action as a first responder is as important as teaching the physical skills involved in delivering lifesaving CPR and AED interventions. This is because if one knows how to recognise the emergency and calls the emergency medical phone number without delay, the trained dispatchers are capable of guiding even an untrained person to take lifesaving steps before the ambulance arrives. Furthermore, the caller must be willing, if capable, to follow the dispatcher's instructions. With this training, we aimed to effect a better-quality response and minimise delay by reducing the dispatcher-assisted CPR learning curve, to motivate trainees to respond quickly and ultimately provide future generations of prepared youth for the country.

The advantages of training children in their schools are compelling. CPR/AED training in schools helps to expose a great number of people to such knowledge and skills; it also leverages a multiplier effect by teaching children, who in turn teach family 
members and friends. School-based training also levels the playing field among classes in society for those with fewer resources who are less likely to be CPR/AED-trained. Finally, school-based training utilises the teaching environment and structure of schools for added sustainability. ${ }^{(5)}$ With these advantages, implementing a training requirement in school is an important step forward towards fostering a culture of action, which has been appropriately supported in the Institute of Medicine's recent report on cardiac arrest. $^{(24)}$

For many students, this was their first exposure to firstresponder training. School-based training sensitises children at an early age to recognise a collapse and imparts the necessary sense of urgency to act right away. ${ }^{(2,25)}$ In our study, researchers had an opportunity to observe any shifts in knowledge and attitude towards CPR/AED, and to better understand what areas may need more emphasis. Although our students gained overall knowledge and were more willing to perform CPR and AED to help others after training, there was lingering concern about harming the victim. This can be seen in the high pre- and posttraining survey response to Question 7a, where students felt less likely to perform CPR and AED because they were scared that they 'might accidentally hurt the victim'. Also, this could explain why secondary school students frequently selected the response'I feel my duty as a bystander is just to call the ambulance and wait for help to arrive' to the same question, even in the post-training survey. This area of concern requires some more emphasis during training, so that it does not become a barrier to the appropriate response, particularly if the victim should be a loved one or acquaintance. Generally, this persistent concern was observed across all school grade levels. However, interestingly, it was the older students' shift from their pre-training response that they had not been trained to one in which they expressed concern about hurting the victim that was the main driver of the survey result we observed.

There could be two explanations for this shift. One possibility is that more emphasis is needed in our training that someone in cardiac arrest is more likely to be helped by the bystander's CPR/ AED efforts rather than being hurt by the attempts to help. The second may be related to survey design, wherein the choices that the students were asked to select from influenced the findings. It is possible that the older students felt that they had few other plausible multiple choice options in the post-training survey. As these junior college students had just been trained, they would not say they had not been taught what to do. Having understood the training message, dialling '995' and waiting for the ambulance's arrival was not a likely option. Older students were also unlikely to indicate that they were afraid of being scolded. Hence, the only viable remaining option apart from 'other' in the posttraining survey was being afraid that they might accidentally hurt the victim while doing CPR. Our results may have been a combination of real concern about hurting the victim and the few post-training choices that were available to this relatively more mature student cohort.

Fear of harming the victim is not uncommon and was reported in another similar study. ${ }^{(20)}$ Indeed, this anxiety is shared by many laypeople training in basic life support and is addressed in our training video. It might be that through gaining a deeper understanding of OHCA and the necessary trade-offs of CPR (e.g. broken ribs with a better chance of survival vs. poorer outcomes without (PR), this anxiety can be replaced with a fearless resolve to save the victim's life. Trainers must strongly emphasise this necessary trade-off during CPR training to impress upon students the importance of bystander CPR in cases of OHCA. Upon calling the emergency number, the dispatchers are trained to calm and reassure the caller as they guide them through the steps of CPR and AED use.

The study also showed that remembering to dial '995' is critical. An encouraging finding was that having 'a person of authority to guide me' was the second most frequently selected response to Question 10 of the post-training survey, which asked students to identify what aspect of the training they liked most. This result could be because students understood that they could call the emergency number and a trained dispatcher would guide them through CPR/AED use, thus somewhat allaying their anxiety about forgetting what to do. It could also be that they liked the idea that someone would be there to act as a virtual witness to their resuscitation attempts and thus felt safe from criticism. Regardless of the reasons for such a favourable ranking, some observations can be made: (a) students understood that they needed to call the emergency number; (b) with dispatcher support, they were not left alone to conduct CPR; and (c) they felt a sense of relief from not having to fear doing something wrong, because someone of authority was there to guide them through the process.

It is critical that CPR/AED trainings help trainees to understand that feeling anxious is a normal part of resuscitation, but in the face of that, they must adopt a lifesaver mentality. We believe this mentality can be enhanced through enriching a student's perspective about what is at stake in a resuscitation attempt. One idea we found particularly constructive was reported in a Belgian study conducted by Stroobants et al, (26) which demonstrated successful attitude changes resulting from schoolchildren teaching basic life support to their network of family and friends. This could be particularly successful in Singapore if it were part of a school assignment. By having children teach their newly acquired knowledge and skill, they would acquire a deeper understanding of CPR training and develop a stronger commitment to doing it, while appreciating afresh that such efforts could even save the life of a loved one. At the same time, this would increase the dispersion of CPR knowledge. This dispersion mechanism would be repeated as successive students enter the school system.

This study was predicated on the belief that students can play an important role in the effort to increase Singapore's bystander CPR rate in the future. Scaling up the number of schools trained and even making it a mandatory part of the course curriculum are policy suggestions that are worth considering in Singapore. Future research will determine whether the efforts we now make will bear fruit, but our study will presumably form a significant part of the baseline against which researchers will measure progress.

The present study was not without limitations. No posttraining follow-up was done to check retention of knowledge 
and skills among participating students. Knowledge and skill retention of learners are important considerations, because the need to use CPR/AED may not arise for many years, if at all, after training. Studies have shown that there is a drop in skill retention when tested six months after initial training. ${ }^{(27,28)}$ We do not doubt nor underrate the importance of a drop-off in knowledge and skill post training. However, based particularly on the high rate of correct recall of Singapore's emergency number in both the pre-training $(72.3 \%$ overall) and post-training (99.2\% overall) surveys, most of our trainees should remember to call it in the event of an emergency. If so, the trained dispatcher would guide them through the various CPR/AED steps, which theoretically would be able to offset any knowledge and/or skill drop-off that may have occurred over time.

Our survey questions could have had the unforeseen consequence of artificially shifting the results we observed for Question 7a on the likelihood of doing CPR, to the extent that results did not truly reflect how the students felt. This may have caused an underestimation of the positive impact of our training on students' attitudes. Some caution in interpreting this result is therefore warranted.

In conclusion, following a video-based CPR/AED training with hands-on practice, a pilot group of Singapore schoolchildren demonstrated CPR/AED knowledge acquisition, showing mostly desirable shifts in how they felt about responding to OHCA and a good response to the training medium. However, in some key areas, we observed certain concerns and misconceptions among schoolchildren prior to training that remained post training. These observations should inform public training targeted at Singapore's youth.

\section{REFERENCES}

1. Bollig G, Myklebust AG, Østringen K. Effects of first aid training in the kindergarten--a pilot study. Scand J Trauma Resusc Emerg Med 2011; 19:13.

2. Cave DM, Aufderheide TP, Beeson J, et al; American Heart Association Emergency Cardiovascular Care Committee; Council on Cardiopulmonary, Critical Care, Perioperative and Resuscitation; Council on Cardiovascular Diseases in the Young; Council on Cardiovascular Nursing; Council on Clinical Cardiology, and Advocacy Coordinating Committee. Importance and implementation of training in cardiopulmonary resuscitation and automated external defibrillation in schools: a science advisory from the American Heart Association. Circulation 2011; 123:691-706.

3. Fleischhackl R, Nuernberger A, Sterz F, et al. School children sufficiently apply life supporting first aid: a prospective investigation. Crit Care 2009; 13:R127.

4. Isbye DL, Meyhoff CS, Lippert FK, Rasmussen LS. Skill retention in adults and in children 3 months after basic life support training using a simple personal resuscitation manikin. Resuscitation 2007; 74:296-302.

5. Bohn A, Van Aken H, Lukas RP, Weber T, Breckwoldt J. Schoolchildren as lifesavers in Europe - training in cardiopulmonary resuscitation for children. Best Pract Res Clin Anaesthesiol 2013; 27:387-96.

6. Bur A, Kittler H, Sterz F, et al. Effects of bystander first aid, defibrillation and advanced life support on neurologic outcome and hospital costs in patients after ventricular fibrillation cardiac arrest. Intensive Care Med 2001; 27:1474-80.

7. Holmberg M, Holmberg S, Herlitz J; Swedish Cardiac Arrest Registry. Factors modifying the effect of bystander cardiopulmonary resuscitation on survival in out-of-hospital cardiac arrest patients in Sweden. Eur Heart J 2001; 22:511-9.

8. Herlitz J, Engdahl J, Svensson L, et al. Factors associated with an increased chance of survival among patients suffering from an out-of-hospital cardiac arrest in a national perspective in Sweden. Am Heart J 2005; 149:61-6.

9. Sasson C, Rogers MA, Dahl J, Kellermann AL. Predictors of survival from out-ofhospital cardiac arrest: a systematic review and meta-analysis. Circ Cardiovasc Qual Outcomes 2010; 3:63-81.

10. Gallagher EJ, Lombardi G, Gennis P. Effectiveness of bystander cardiopulmonary resuscitation and survival following out-of-hospital cardiac arrest. JAMA 1995; 274:1922-5.

11. Lai $\mathrm{H}$, Choong $\mathrm{CV}$, Fook-Chong $\mathrm{S}$, et al; PAROS study group. Interventional strategies associated with improvements in survival for out-of-hospital cardiac arrests in Singapore over 10 years. Resuscitation 2015; 89:155-61.

12. Yong WW, Kua PH, Soon SS, Pek PP, Hock Ong ME. DARE train-the-trainer pedagogy development using 2-round Delphi methodology. Biomed Res Int 2016; 2016:5460964.

13. Berdowski J, Berg RA, Tijssen JG, Koster RW. Global incidences of out-of-hospital cardiac arrest and survival rates: systematic review of 67 prospective studies. Resuscitation 2010; 81:1479-87.

14. Hasselqvist-Ax I, Riva G, Herlitz J, et al. Early cardiopulmonary resuscitation in out-of-hospital cardiac arrest. N Engl J Med 2015; 372:2307-15.

15. Wissenberg M, Lippert FK, Folke F, et al. Association of national initiatives to improve cardiac arrest management with rates of bystander intervention and patient survival after out-of-hospital cardiac arrest. JAMA 2013; 310:1377-84.

16. Gräsner JT, Lefering R, Koster RW, et al; EuReCa ONE Collaborators. EuReCa ONE-27 Nations, ONE Europe, ONE Registry: A prospective one month analysis of out-of-hospital cardiac arrest outcomes in 27 countries in Europe. Resuscitation 2016; 105:188-95.

17. Strömsöe A, Svensson L, Axelsson ÅB, et al. Improved outcome in Sweden after out-of-hospital cardiac arrest and possible association with improvements in every link in the chain of survival. Eur Heart J 2015; 36:863-71.

18. Boyce LW, Vliet Vlieland TP, Bosch J, et al. High survival rate of $43 \%$ in outof-hospital cardiac arrest patients in an optimised chain of survival. Neth Heart J 2015; 23:20-5.

19. Lind B, Stovner J. Mouth-to-mouth resuscitation in Norway. JAMA 1963; 185:933-5

20. Kanstad BK, Nilsen SA, Fredriksen K. CPR knowledge and attitude to performing bystander CPR among secondary school students in Norway. Resuscitation $2011 ; 82: 1053-9$

21. Tjomsland N, Laerdal T, Baskett P. Resuscitation great: Bjorn Lind--the groundbreaking nurturer. Resuscitation 2005; 65:133-8.

22. Plant N, Taylor K. How best to teach CPR to schoolchildren: a systematic review. Resuscitation 2013; 84:415-21.

23. Böttiger BW, Van Aken H. Kids save lives--Training school children in cardiopulmonary resuscitation worldwide is now endorsed by the World Health Organization (WHO). Resuscitation 2015; 94:A5-7.

24. Institute of Medicine. Strategies to improve cardiac arrest survival: A time to act. Washington, DC: The National Academies Press. 2015.

25. Pantin HM, Carver CS. Induced competence and the bystander effect. J Appl Soc Psychol 1982; 12:100-11.

26. Stroobants J, Monsieurs K, Devriendt B, et al. Schoolchildren as BLS instructors for relatives and friends: impact on attitude towards bystander CPR. Resuscitation 2014; 85:1769-74.

27. Woollard M, Whitfield R, Newcombe RG, et al. Optimal refresher training intervals for AED and CPR skills: a randomised controlled trial. Resuscitation 2006; 71:237-47.

28. Lester CA, Weston CF, Donnelly PD, Assar D, Morgan MJ. The need for wider dissemination of CPR skills: are schools the answer? Resuscitation 1994; 28:233-7. 


\section{APPENDIX 1}

\section{Pre-training survey}

Class Participant Number

Dear Student, this is a simple 10-question survey about your knowledge, attitudes and beliefs about CPR (Cardio-Pulmonary Resuscitation) \& AED (Automated External Defibrillator) today. Your response will help us understand how to teach you better. Your grades will not be affected by this so please answer truthfully and do not guess what the 'correct' answer is.

1. What is the first thing you should do if you see a person collapse?
a) Check for danger and move him away if necessary.
b) Call for help.
c) Start chest compressions.
d) Use an AED.
e) I don't know.

2. What is the correct number you should dial for an emergency ambulance?
a) 911 .
b) 995 .
c) 999 .
d) 1777 .
e) I don't know.

3. What should you do after you get through to the dispatcher on the emergency line?
a) Shout 'help' and put the phone down quickly.
b) Give my current location and put the phone down quickly.
c) Stay on the line while the dispatcher teaches me how to do CPR until the ambulance arrives.
d) Do not stay on the line as that will delay the ambulance.
e) I don't know.

4. How deep should chest compressions be done for a collapsed person?
a) $1 \mathrm{~cm}$
b) $5 \mathrm{~cm}$
c) $10 \mathrm{~cm}$
d) No specific depth, as long as I am gentle.
e) I don't know.

5. How fast should chest compressions be done for a collapsed person?
a) 30 per minute.
b) 60 per minute.
c) 100 per minute.
d) No specific rate, as long as it is slow.
e) I don't know.

6. How likely are you to perform CPR on a collapsed person today?
a) Very unlikely.
b) Unlikely.
c) I don't know.
d) Likely.
e) Very likely. 
If you answered a, b, c to Question 6, please proceed to Question 7a and do not answer 7b.

If you answered d, e to Question 6, please proceed to Question 7b and do not answer 7a.

7a. What is the most important reason why you are less likely to do CPR on a collapsed person today?

a) I am scared I might accidentally hurt the victim.

b) I feel my duty as a bystander is just to call the ambulance and wait for help to arrive.

c) I have never been taught what to do.

d) I do not want to be scolded if I do the wrong thing.

e) Others (please specify):

7b. What is the most important reason why you are likely to do CPR on a collapsed person today?
a) I feel I am more likely to help a person who has already collapsed, than do him harm.
b) I feel it is my duty to help someone in need.
c) I have been taught how to do CPR before.
d) I have been encouraged to help others in need.
e) Others (please specify):

8. How likely are you to use an AED on a collapsed person today?
a) Very unlikely
b) Unlikely
c) I don't know
d) Likely
e) Very likely

If you answered a, b, c to Question 8, please proceed to Question 9a and do not answer 9b.

If you answered d, e to Question 8, please proceed to Question 9b and do not answer 9a.

9a. What is the most important reason why you are less likely to use an AED today?
a) I am scared I might accidentally hurt the victim.
b) I feel my duty as a bystander is just to call the ambulance and wait for help to arrive.
c) I have never been taught what to do.
d) I do not want to be scolded if I do the wrong thing.
e) Others (please specify):

9b. What is the most important reason why you are likely to use an AED today?
a) I feel I am more likely to help a person who has already collapsed, than do him harm.
b) I feel it is my duty to help someone in need.
c) I have been taught how to use an AED before.
d) I have been encouraged to help others in need.
e) Others (please specify):

10. What would you like to have in a class about CPR/AED? You may circle more than 1 answer.
a) A humorous video.
b) A person of authority to guide me through the video.
c) Real-life accounts of survivors and rescuers.
d) Lecture notes or an instruction manual to bring home.
e) Others (please specify): 


\section{APPENDIX 2}

\section{Post-training survey}

Class Participant Number

Dear Student, this is a simple 10-question survey about your knowledge, attitudes and beliefs about CPR (Cardio-Pulmonary Resuscitation) \& AED (Automated External Defibrillator) today. Your response will help us understand how to teach you better. Thank you for your participation!

1. What is the first thing you should do if you see a person collapse?
a) Check for danger and move him away if necessary.
b) Call for help.
c) Start chest compressions.
d) Use an AED.
e) I don't know.

2. What is the correct number you should dial for an emergency ambulance?
a) 911 .
b) 995 .
c) 999 .
d) 1777 .
e) I don't know.

3. What should you do after you get through to the dispatcher on the emergency line?
a) Shout 'help' and put the phone down quickly.
b) Give my current location and put the phone down quickly.
c) Stay on the line while the dispatcher teaches me how to do CPR until the ambulance arrives.
d) Do not stay on the line as that will delay the ambulance.
e) I don't know.

4. How deep should chest compressions be done for a collapsed person?
a) $1 \mathrm{~cm}$.
b) $5 \mathrm{~cm}$.
c) $10 \mathrm{~cm}$.
d) No specific depth, as long as I am gentle.
e) I don't know.

5. How fast should chest compressions be done for a collapsed person?
a) 30 per minute
b) 60 per minute
c) 100 per minute
d) No specific rate, as long as it is slow
e) I don't know

6. How likely are you to perform CPR on a collapsed person today?
a) Very unlikely
b) Unlikely
c) I don't know
d) Likely
e) Very likely 
If you answered a, b, c to Question 6, please proceed to Question 7a and do not answer 7b.

If you answered d, e to Question 6, please proceed to Question 7b and do not answer 7a.

7a. What is the most important reason why you are less likely to do CPR on a collapsed person today?
a) I am scared I might accidentally hurt the victim.
b) I feel my duty as a bystander is just to call the ambulance and wait for help to arrive.
c) I have never been taught what to do.
d) I do not want to be scolded if I do the wrong thing.
e) Others (please specify):

7b. What is the most important reason why you are likely to do CPR on a collapsed person today?
a) I feel I am more likely to help a person who has already collapsed, than do him harm.
b) I feel it is my duty to help someone in need.
c) I have been taught how to do CPR before.
d) I have been encouraged to help others in need.
e) Others (please specify):

8. How likely are you to use an AED on a collapsed person today?
a) Very unlikely
b) Unlikely
c) I don't know
d) Likely
e) Very likely

If you answered a, b, c to Question 8, please proceed to Question 9a and do not answer 9b. If you answered d, e to Question 8, please proceed to Question 9b and do not answer 9a.

9a. What is the most important reason why you are less likely to use an AED today?
a) I am scared I might accidentally hurt the victim.
b) I feel my duty as a bystander is just to call the ambulance and wait for help to arrive.
c) I have never been taught what to do.
d) I do not want to be scolded if I do the wrong thing.
e) Others (please specify):

9b. What is the most important reason why you are likely to use an AED today?
a) I feel I am more likely to help a person who has already collapsed, than do him harm.
b) I feel it is my duty to help someone in need.
c) I have been taught how to use an AED before.
d) I have been encouraged to help others in need.
e) Others (please specify):

10. What aspects of this class on CPR/AED did you enjoy? You may circle more than 1 answer.
a) A humorous video.
b) A person of authority to guide me through the video.
c) Real-life accounts of survivors and rescuers.
d) Lecture notes or an instruction manual to bring home.
e) Others (please specify):

11. If you have any further comments or questions, please feel free to write them. We will address them and send our replies back to you through your school. 